\title{
Comparison of active learning models in schools in increasing the cognitive value of students
}

\author{
Tulus $^{1 *}$, Muhammad Zarlis ${ }^{2}$, Sawaluddin ${ }^{3}$, Romi Syahputra ${ }^{4}$ \\ 1,3,4 Departement of Mathematics, Universitas Sumatera Utara, Medan, Indonesia \\ ${ }^{2}$ Departement of Information Technology, Universitas Sumatera Utara, Medan, Indonesia \\ *Email: tulus@usu.ac.id
}

\begin{abstract}
The term learning model is distinguished from the term learning strategy, method learning or learning procedure. The term learning model has broader meaning than a strategy, approach, method or procedure. Learning models are patterns of interaction between students, teachers, and material learning that includes strategies, approaches, methods and techniques learning. Elaborate that learning strategies are tactics or tips planned by the teacher related to the whole preparation of learning can be achieved effectively. While the approach is the way taken by the teacher in the implementation of learning so that the active ideas presented can be adapted to then be understood by students. There are two types of active learning, namely: a methodological approach and material approach. Methodological approach concerns the way students Adapting the active ideas presented into their cognitive structures that are in line in the way taken by the teacher in presenting learning materials the. Examples of methodological approaches are intuitive, analytic, synthetic, spiral, inductive, deductive, thematic, realistic and heuristic. The result of this research is the material approach able to present an active concept through other active concepts already owned by students. The example presents the concept of addition with using the number line or set approach.
\end{abstract}

Keyword: Learning, Model, Cognitif, Strategies

\begin{abstract}
Abstrak
Istilah model pembelajaran dibedakan dari istilah strategi pembelajaran, metode pembelajaran atau prosedur pembelajaran. Istilah model pembelajaran mempunyai makna yang lebih luas dari pada suatu strategi, pendekatan, metode atau prosedur. Model pembelajaran adalah pola interaksi antara siswa, guru, dan materi pembelajaran yang mencakup strategi, pendekatan, metode dan Teknik pembelajaran menguraikan bahwa strategi pembelajaran adalah siasat atau kiat yang direncanakan oleh guru terkait dengan segenap persiapan pembelajaran dapat dicapai secara efektif. Sedangkan pendekatan adalah carayang ditempuh oleh guru dalam pelaksanaan pembelajaran agar ide aktif yang disajikan dapat diadaptasi untuk kemudian dipahami oleh siswa. Terdapat dua jenis pembelajaran aktif, yaitu: pendekatan yang bersifat metodologis dan pendekatan material. Pendekatan metodologis menyangkut cara siswa mengadaptasi ide aktif yang disajikan ke dalam struktur kognitifnya yang sejalan dengan cara yang ditempuh oleh Guru dalam menyajikan bahan pembelajaran tersebut. Contoh pendekatan metodologis adalah pendekatan intuitif, analitik, sintetik, spiral, induktif, deduktif, tematik, realistik dan heuristik. Hasil yang dicapai pada pengabdian ini adalah pendekatan material yang dapat menyajikan konsep aktif melalui konsep aktif lain yang telah dimiliki siswa. Contohnya menyajikan konsep penjumlahan dengan menggunakan pendekatan garis bilangan atau himpunan.
\end{abstract}

Kata Kunci: Pembelajaran, Model, kognitif, Strategi

\section{PENDAhUluan}

Model pembelajaran mempunyai sejumlah ciri khas yang tidak dipunyai oleh strategi atau metode tertentu yaitu: rasional teoritik yang logis dan kuat yang disusun oleh pengembangnya; sintaks yang berupa tingkah laku atau pola atau langkah pembelajaran yang diperlukan agar model tersebut dapat dilaksanakan dengan sukses; sistem sosial yang berupa kaidah atau tata aturan yang 
dirancang dan disepakati untuk dijalankan dalam proses pembelajaran, prinsip reaksi yang menata bagaimana interaksi antar semua pihak yang terlibat dalam proses pembelajaran seharusnya berlangsung; sistem pendukung berupa perangkat pembelajaran dan perlengkapan lainnya baik untuk guru maupun untuk siswa dan untuk proses pembelajaran yang akan dilaksanakan; dan dampak intruksional berupa tujuan pembelajaran yang akan dicapai baik secara langsung maupun berupa dampak pengiring (nurturant effenct). Terdapat ahli pengembangan model pembelajaran yang tidak memasukkan rasional teoritik sebagai komponen dari sebuah model pembelajaran. Alasannya adalah bahwa setiap model yang dikembangkan pasti mengacu atau berlandaskan pada beragam teori. Akan diuraikan tiga model pembelajaran yaitu model pembelajaran langsung, model pembelajaran kooperatif dan model pembelajaran berbasis masalah.

\subsection{Model Pembelajaran Langsung}

Model pembelajaran langsung atau model pengajaran langsung (directed instruction) bertumpu pada prinsip-prinsip psikologi prilaku dan teori belajar sosial khususnya tentang pemodelan (modeling). Hal ini didasarkan pada kenyataan bahwa perubahan perilaku dalam belajar sebagian besar diperoleh dari pemodelan, yaitu perilaku dan pengalaman (keberhasilan dan kegagalan) orang lain. Oleh karena itu, pembelajaran langsung merupakan model pengajaran yang bersifat teacher centered.

\subsection{Model Pembelajaran Kooperatif}

Pembelajaran kooperatif dilakukan dengan membentuk kelompok kecil yang anggotanya heterogen untuk bekerja sebagai sebuah tim dalam menyelesaikan masalah, tugas atau mengerjakan sesuatu untuk mencapai tujuan bersama. Menurut teori motivasi, bentuk hadiah atau struktur pencapaian tujuan saat siswa melakukan kegiatan merupakan motivasi dalam pembelajaran kooperatif. Struktur tujuan kooperatif menciptakan suatu situasi bahwa tujuan pribadi dapat tercapai hanya apabila kelompok itu berhasil. Sebelum pembelajaran kooperatif diterapkan, siswa perlu mengetahui ketrampilan-ketrampilan kooperatif yang akan digunakan bekerja dalam tim. Model pembelajaran ini sejalan dengan salah satu prinsip CTL yaitu learning community.

\subsection{Model Pembelajaran Berbasis Masalah}

Model pembelajaran berbasis masalah dapat menyajikan masalah autentik dan bermakna sehingga siswa dapat melakukan penyelidikan dan menemukan sendiri. Peranan Guru dalam model ini adalah mengajukan masalah, memfasilitasi penyelidikan dan interaksi siswa. Model pembelajaran ini ini berlandaskan psikologi kognitif dan pandangan konstruktif mengenai belajar. Model ini jugasesuai prinsip-prinsip CTL yakni inkuiri, kontruktivisme dan menekankan padaber pikir tingkat lebih tinggi.

\section{METODE PELAKSANAAN}

Dalam pelaksanaan metode pembelajaran disekolah terdapat beberapa metode yang digunakan dalam hal pelaksanaan kegiatan belajar mengajar yaitu:

1. Pengantar

2. Diskusi dengan 3 model pembelajaran

3. Diskusi kelompok model kooperatif tipe jigsaw

4. Penutup 
Tulus et.al. Comparison of active learning models

\section{HASIL DAN PEMBAHASAN}

\subsection{Model Pembelajaran Langsung}

Sintaks Model Pembelajaran Langsung dapat diperhatikan pada Tabel 3.1.

\begin{tabular}{|c|l|l|}
\hline Fase ke & \multicolumn{1}{|c|}{ Indikator } & \multicolumn{1}{c|}{ Aktifitas Guru } \\
\hline 1 & $\begin{array}{l}\text { Menyampaikan tujuan } \\
\text { dan mempersiapkan } \\
\text { siswa }\end{array}$ & $\begin{array}{l}\text { Guru menjelaskan tujuan pembelajaran, } \\
\text { informasi latar belakang pelajaran, entingnya } \\
\text { pelajaran, mempersiapkan siswa untuk belajar. }\end{array}$ \\
\hline 2 & $\begin{array}{l}\text { Mendemontasikan } \\
\text { pengetahuan atau } \\
\text { keterampilan }\end{array}$ & $\begin{array}{l}\text { Guru mendemontrasikan keterampilan yang } \\
\text { benar, atau menyajikan informasi tahap demi } \\
\text { tahap. }\end{array}$ \\
\hline 3 & Membimbing pelatihan & $\begin{array}{l}\text { Guru merencanakan dan memberi bimbingan } \\
\text { pelatihan awal. }\end{array}$ \\
\hline 5 & $\begin{array}{l}\text { Mengecek pemahaman } \\
\text { dan memberi umpan balik }\end{array}$ & $\begin{array}{l}\text { Guru mengecek apakah siswa telah berhasil } \\
\text { melakukan tugas dengan baik, memberi umpan } \\
\text { balik. }\end{array}$ \\
\hline 5 & $\begin{array}{l}\text { Memberikan } \\
\text { kesempatan untuk } \\
\text { pelatihan dan } \\
\text { penerapan }\end{array}$ & $\begin{array}{l}\text { Guru mempersiapkan kesempatan melakukan } \\
\text { pelatihan lanjutan dengan pelatihan khusus pada } \\
\text { penerapan kepada situasi lebih kompleks dan } \\
\text { masalah-masalah yang berkaitan dengan } \\
\text { kehidupan sehari-hari. }\end{array}$ \\
\hline
\end{tabular}

Tabel 3.1 Sintaks Model Pembelajaran Langsung

\subsection{Sintaks Model Pembelajaran Kooperatif}

Sintaks Model Pembelajaran kooperatif dapat diperhatikan pada Tabel 3.2.

\begin{tabular}{|c|l|l|}
\hline Fase ke & \multicolumn{1}{|c|}{ Indikator } & \multicolumn{1}{c|}{ Aktifitas Guru } \\
\hline 1 & $\begin{array}{l}\text { Menyampaikan tujuan } \\
\text { dan memotivasi siswa }\end{array}$ & $\begin{array}{l}\text { Guru menyampaikan tujuan pembelajaran } \\
\text { (standar kompetensi) yang ingin dicapai } \\
\text { pada pelajaran tersebut dan memotivasi } \\
\text { siswa belajar. }\end{array}$ \\
\hline 2 & Menyajikan informasi & $\begin{array}{l}\text { Guru menyajikan informasi kepada siswa } \\
\text { dengan jalan demonstrasi atau lewat bahan } \\
\text { bacaan. }\end{array}$ \\
\hline 3 & $\begin{array}{l}\text { Mengorganisasikan } \\
\text { siswa ke dalam } \\
\text { kelompok-kelompok } \\
\text { belajar }\end{array}$ & $\begin{array}{l}\text { Guru menjelaskan kepada siswa } \\
\text { bagaimana cara membentuk kelompok } \\
\text { belajar dan membantu setiap kelompok } \\
\text { agar melakukan perubahan yang efisien. }\end{array}$ \\
\hline 4 & $\begin{array}{l}\text { Membimbing kelompok } \\
\text { bekerja dan belajar }\end{array}$ & $\begin{array}{l}\text { Guru membimbing kelompok-kelompok } \\
\text { belajar pada saat mereka mengerjakan } \\
\text { tugas dalam hal menggunakan ketrampilan } \\
\text { kooperatif. }\end{array}$ \\
\hline 5 & Evaluasi & $\begin{array}{l}\text { Guru mengevaluasi hasil belajar tentang } \\
\text { materi yang telah dipelajari atau masingmasing } \\
\text { kelompok menyajikan hasil } \\
\text { kerjanya. }\end{array}$ \\
\hline
\end{tabular}


Tulus et.al. Comparison of active learning models

\begin{tabular}{|c|l|l|}
\hline Fase ke & \multicolumn{1}{|c|}{ Indikator } & \multicolumn{1}{c|}{ Aktifitas Guru } \\
\hline 6 & $\begin{array}{l}\text { Memberikan } \\
\text { penghargaan }\end{array}$ & $\begin{array}{l}\text { Guru memberikan cara-cara untuk menghargai, } \\
\text { baik upaya maupun hasil belajar individu dan } \\
\text { kelompok. }\end{array}$ \\
\hline
\end{tabular}

Tabel 3.2 Sintaks Model Pembelajaran Kooperatif

\subsection{Sintaks Model Pembelajaran Berbasis Masalah}

Sintaks Model Pembelajaran Berbasis Masalah dapat diperhatikan pada Tabel 3.3.

\begin{tabular}{|c|l|l|}
\hline Fase ke & \multicolumn{1}{|c|}{ Indikator } & \multicolumn{1}{c|}{ Aktifitas Guru } \\
\hline 1 & $\begin{array}{l}\text { Orientasi siswa kepada } \\
\text { masalah }\end{array}$ & $\begin{array}{l}\text { Guru menjelaskan tujuan pembelajaran, } \\
\text { menjelaskan logistik yang dibutuhkan, } \\
\text { memotivasi siswa terlibat pada aktivitas } \\
\text { pemecahan masalah yang dipilihnya. }\end{array}$ \\
\hline 2 & $\begin{array}{l}\text { Mengorganisasikan siswa } \\
\text { untuk belajar }\end{array}$ & $\begin{array}{l}\text { Guru membantu siswa mendefinisikan } \\
\text { dan mengorganisasikan tugas belajar } \\
\text { yang berhubungan dengan masalah } \\
\text { tersebut. }\end{array}$ \\
\hline 3 & $\begin{array}{l}\text { Membimbing } \\
\text { penyelidikan } \\
\text { individual maupun } \\
\text { kelompok }\end{array}$ & $\begin{array}{l}\text { Guru mendorong siswa untuk } \\
\text { mengumpulkan informasi yang sesuai, } \\
\text { melaksanakan eksperimen untuk } \\
\text { mendapatkan penjelasan dan pemecahan } \\
\text { masalah. }\end{array}$ \\
\hline 4 & $\begin{array}{l}\text { Mengembangkan dan } \\
\text { menyajikan hasil karya }\end{array}$ & $\begin{array}{l}\text { Guru membantu siswa dalam } \\
\text { merencanakan dan menyiapkan karya } \\
\text { yang sesuai seperti laporan, video, model } \\
\text { dan membantu mereka untuk berbagi } \\
\text { tugas dengan temannya. }\end{array}$ \\
\hline 5 & $\begin{array}{l}\text { Menganalisis dan } \\
\text { mengevaluasi proses } \\
\text { pemecahan masalah }\end{array}$ & $\begin{array}{l}\text { Guru membantu siswa untuk melakukan } \\
\text { refleksi atau evaluasi terhadap } \\
\text { penyelidikan mereka dan proses-proses } \\
\text { yang mereka gunakan. }\end{array}$ \\
\hline 6 & $\begin{array}{l}\text { Memberikan } \\
\text { penghargaan } \\
\text { baik upaya maupun hasil belajar individu dan } \\
\text { kelompok. }\end{array}$ \\
\hline
\end{tabular}

Tabel 3.3 Sintaks Model Pembelajaran Berbasis Masalah 
Tulus et.al. Comparison of active learning models

\subsection{Perbandingan Aktifitas Guru pada Model Pembelajaran}

\begin{tabular}{|c|c|c|c|}
\hline \multirow{2}{*}{ Fase } & \multicolumn{3}{|c|}{ Aktifitas Guru } \\
\hline & Langsung & Kooperatif & Berbasis Masalah \\
\hline 1 & $\begin{array}{l}\text { Guru menjelaskan tujuan pembelajaran, } \\
\text { informasi latar belakang pelajaran, entingnya } \\
\text { pelajaran, mempersiapkan siswa untuk belajar. }\end{array}$ & $\begin{array}{l}\text { Guru menyampaikan tujuan pembelajaran } \\
\text { (standar kompetensi) yang ingin dicapai } \\
\text { pada pelajaran tersebut dan memotivasi } \\
\text { siswa belajar. }\end{array}$ & $\begin{array}{l}\text { Guru menjelaskan tujuan pembelajaran, } \\
\text { menjelaskan logistik yang dibutuhkan, } \\
\text { memotivasi siswa terlibat pada aktivitas } \\
\text { pemecahan masalah yang dipilihnya. }\end{array}$ \\
\hline 2 & $\begin{array}{l}\text { Guru mendemontrasikan keterampilan yang } \\
\text { benar, atau menyajikan informasi tahap demi } \\
\text { tahap. }\end{array}$ & $\begin{array}{l}\text { Guru menyajikan informasi kepada siswa } \\
\text { dengan jalan demonstrasi atau lewat bahan } \\
\text { bacaan. }\end{array}$ & $\begin{array}{l}\text { Guru membantu siswa mendefinisikan } \\
\text { dan mengorganisasikan tugas belajar } \\
\text { yang berhubungan dengan masalah } \\
\text { tersebut. }\end{array}$ \\
\hline 3 & $\begin{array}{l}\text { Guru merencanakan dan memberi bimbingan } \\
\text { pelatihan awal. }\end{array}$ & $\begin{array}{l}\text { Guru menjelaskan kepada siswa } \\
\text { bagaimana cara membentuk kelompok } \\
\text { belajar dan membantu setiap kelompok } \\
\text { agar melakukan perubahan yang efisien. }\end{array}$ & $\begin{array}{l}\text { Guru mendorong siswa untuk } \\
\text { mengumpulkan informasi yang sesuai, } \\
\text { melaksanakan eksperimen untuk } \\
\text { mendapatkan penjelasan dan pemecahan } \\
\text { masalah. }\end{array}$ \\
\hline 4 & $\begin{array}{l}\text { Guru mengecek apakah siswa telah berhasil } \\
\text { melakukan tugas dengan baik, memberi umpan } \\
\text { balik. }\end{array}$ & $\begin{array}{l}\text { Guru membimbing kelompok-kelompok } \\
\text { belajar pada saat mereka mengerjakan } \\
\text { tugas dalam hal menggunakan ketrampilan } \\
\text { kooperatif. }\end{array}$ & $\begin{array}{l}\text { Guru membantu siswa dalam } \\
\text { merencanakan dan menyiapkan karya } \\
\text { yang sesuai seperti laporan, video, model } \\
\text { dan membantu mereka untuk berbagi } \\
\text { tugas dengan temannya. }\end{array}$ \\
\hline 5 & $\begin{array}{l}\text { Guru mempersiapkan kesempatan melakukan } \\
\text { pelatihan lanjutan dengan pelatihan khusus } \\
\text { pada penerapan kepada situasi lebih kompleks } \\
\text { dan masalah-masalah yang berkaitan dengan } \\
\text { kehidupan sehari-hari. }\end{array}$ & $\begin{array}{l}\text { Guru mengevaluasi hasil belajar tentang } \\
\text { materi yang telah dipelajari atau } \\
\text { masingmasing kelompok menyajikan hasil } \\
\text { kerjanya. }\end{array}$ & $\begin{array}{l}\text { Guru membantu siswa untuk melakukan } \\
\text { refleksi atau evaluasi terhadap } \\
\text { penyelidikan mereka dan proses-proses } \\
\text { yang mereka gunakan. }\end{array}$ \\
\hline 6 & & $\begin{array}{l}\text { Guru memberikan cara-cara untuk } \\
\text { menghargai, baik upaya maupun hasil } \\
\text { belajar individu dan kelompok. }\end{array}$ & $\begin{array}{l}\text { Guru memberikan cara-cara untuk } \\
\text { menghargai, baik upaya maupun hasil } \\
\text { belajar individu dan kelompok. }\end{array}$ \\
\hline
\end{tabular}

Tabel 3.4 Perbandingan Aktifitas Guru 


\section{KESIMPULAN}

Pemanfaatan model pembelajaran memiliki tujuan yang berbeda tergantung kondisi lingkungan sekolah maka dapat disimpulkan tujuan masing masing model pembelajaran adalah:

1. Model Pembelajaran Kooperatif

a. Membantu siswa untuk mencapai hasil belajar optimal dan mengembangkan ketrampilan sosial siswa.

b. Mengajarkan ketrampilan bekerjasama dan berkolaborasi.

2. Model Pembelajaran langsung

a. Membantu siswa untuk memperoleh pengetahuan prosedural, yaitu pengetahuan tentang bagaimana melakukan sesuatu. Misalnya bagaimana cara menggunakan alat dalam melakukan suatu eksperimen.

b. Membantu untuk memahami pengetahuan deklaratif, yaitu pengetahuan tentang sesuatu (dapat diungkapkan dengan kata-kata), misalnya namanama bagian suatu alat.

3. Model Pembelajaran berbasis Masalah

a. Membantu siswa untuk mengembangkan kemampuan berpikir, memecahkan masalah dan ketrampilan intelektual.

b. Melibatkan siswa secara aktif dalam proses pembelajaran melalui pengalaman nyata atau simulasi sehingga ia dapat mandiri.

\section{UCAPAN TERIMAKASIH}

Penulis mengucapkan terima kasih kepada LPPM USU melalui dana Non PNBP Universitas Sumatera Utara sesuai dengan Surat Perjanjian Penugasan Pelaksanaan Pengabdian Kepada Masyarakat Program IBKIK Tahun Anggaran 2017 Nomor : 3223/UN5.2.3.2.1/PPM/2017, Tanggal 24 Juli 2017.

\section{DAFTAR PUSTAKA}

Stahl F, Ashworth SH, Jandt KD, Mills RW. Light-emitting diode (LED) polymerization of dental composites: flexural properties and polymerization potential. J Biomater 2000; 21 : 1379-85.

Beattie, S., 2005, Active Teaching Strategis, Baker College.

Kaufman, D. Sutow, E. \& Dunn, K., Three Approaches to Cooperative Learning in Higher Education, The Canadian Journal of Higher Education, Vol. XXVII, No. 2,3 p. 37-66

Ledlow, S., 1999, Cooperative Learning in Higher Educational, Centre for learning and Teaching Excellence, Arizona State University

Keyser, M. W., Active learning and cooperative learning: understanding the difference and using both styles effectively, Research Strategics, Vol. 17, p. 35-44

Ragains, P. 1995., Four variations in Drueke's active learning paradigm. Research strategies 13 (Winter), 40-50

Suherman, E. dkk. 2003. Strategi Pembelajaran Aktif Kontemporer. Bandung. Universitas Pendidikan Indonesia 